\title{
Triatlón: un enfoque innovador en la enseñanza secundaria
}

\section{Triathlon: an innovative approach in Secondary School Physical Education}

\author{
Machota Blas, V.E.* \\ Jefa de departamento de Educación Fisica. Instituto de Enseñanza Secundaria "Antonio Hellín Costa" (Mazarrón - Murcia)
}

\begin{abstract}
Resumen: Este trabajo presenta la implementación de una unidad didáctica innovadora de Triatlón en un contexto de Educación Física escolar. La propuesta diseńada, integrada en la Programación Docente, introduce a los alumnos a este deporte y fomenta la actividad física en el medio natural como medio de mantenerse activo, saludable y en forma. Los resultados sobre el impacto de la unidad didáctica en los estudiantes fueron estudiados a través de grupos de discusión. Los estudiantes parecen haber tomado conciencia del deporte del Triatlón y demostraron conocimientos y habilidades relacionadas con éste. Esta unidad innovadora les ha proporcionado la oportunidad para aprender estas habilidades y practicar este deporte fuera del ámbito escolar y aumentar sus niveles de actividad física. Su desarrollo inicial puede parecer condicionada a la ubicación y características de material muy específico, pero con las modificaciones apropiadas puede ser adaptado e incluido en la EF escolar.

Palabras clave: Triatlón, Educación Física, Unidad didáctica.
\end{abstract}

Abstract: This paper presents an innovative implementation of Triathlon in a school-based Physical Education context. A teaching unit of Triathlon was designed to become part of the Physical Education Syllabus. It introduced adolescents to Triathlon fostering physical activity in the natural environment to stay active, healthy and fit. The results on the impact of the unit on students were studied through discussions with focus groups. Students seem to have become aware of the sport of Triathlon and demonstrate outcomes on knowledge, understanding and basic skills related to Triathlon. This unit has provided them the opportunities to learn these skills and practise this sport beyond school based Physical Education and increase their levels of physical activity. Its initial development may seem conditioned upon location and characteristics of very specific material, but with appropriate modifications it can be adapted and included in the schoolbased Physical Education Syllabus.

Keywords: Triathlon, Physical Education, Teaching unit.

\section{Introduction}

School-based Physical Education is now aware of a wider range of physical activities and sports. Lessons are now extending beyond traditional sports facing new challenges to make Physical Education relevant to students. Triathlon is a contemporary sport which can contribute to increase participation in physical activity and expand that participation beyond school.

Triathlon has become an extremely popular sport in Spain undergoing an overwhelming growth. The Spanish Sport Authority as the governing body for the sport, in collaboration with the Spanish Triathlon Federation, is promoting Triathlon with modified rules to match various skills and competition levels.

This paper presents an innovative approach and implementation of Triathlon in a school-based Physical Education context in order to understand the impact of this sport on students. The aim of this paper is to present the implementation of triathlon within the School-based Physical Education.

\section{Triathlon: a triple fitness sport}

Triathlon is an endurance sport involving swimming, cycling, and running done in this order and without a break from each other. Triathlons originated in California in the 1970s

Dirección para correspondencia [Correspodence address]: Victoria E. Machota Blas. E-mail: victoriaeugen.machota@murciaeduca.es and the beginnings of the most famous triathlon in the world began to unfold in Hawaii. In 1978 three separate events (3.800 m. Waikiki Rough Water Swim, 180 km. Oahu Bike Race and the Honolulu Marathon, $42.195 \mathrm{~km}$.) were combined to form the Hawaii Ironman Triathlon, considered to be the most prestigious triathlon event in the world. Triathlon has grown in popularity and today there are multiple governing bodies for the sport of triathlon supporting different length races (Internacional Triathlon Union, ITU; International Triathlon Corporation, WTC, etc.). Triathlon became an Olympic event in 2000. Olympic and world championship triathlons consist of a $1.5-\mathrm{km}$ open water swim, a $40-\mathrm{km}$ bicycle ride, and a $10-\mathrm{km}$ run.

Triathlon has different combinations that translate into different modalities with varying distances: triathlon (swim, bike and run), duathlon (run, bike and run) and aquathlon (run, swim and run). There is also the so-called cross triathlon and duathlon cross differentiated by using mountain biking and running on mountain tracks. In addition, there is a winter triathlon that combines run, cycle and skiing and a combination with canoeing, swimming, cycling and running.

Triathlon races vary in distance. The main international race distances are:

1. Sprint Distance; $750 \mathrm{~m}$. swim, $20 \mathrm{~km}$. bike, $5 \mathrm{~km}$. run

2. Olympic distance: $1.5 \mathrm{~km}$. swim, $40 \mathrm{~km}$ bike, $10 \mathrm{~km}$. run 
3. Long Course (Half-Ironman): $1.9 \mathrm{~km}$. swim, $90 \mathrm{~km}$. bike, and a $21.1 \mathrm{~km}$. run

4. Ultra Distance (Ironman): $3.8 \mathrm{~km} \mathrm{swim,} 180.2 \mathrm{~km}$ bike, and $42.2 \mathrm{~km}$ run.

Nevertheless, triathlons are not necessarily restricted to these prescribed distances. Races can be any combination of distance depending on the organizers and the ages to meet. The distances of each of the segments are adapted to the different ages (Torres and Portoles, 2007). Most triathlons are individual events but relay triathlons are now becoming more popular and an excellent option for younger and non-experienced participants. In this case, competitors take turns to complete a triathlon and each of them takes part in only one segment: swimming, cycling or running. Rules for triathlon vary depending on the governing body although there are some basic universal rules such as each triathlete is competing against the course and the non-stop clock for the best time.

\section{Why introduce triathlon in school based-physical education?}

Over the last times, school physical education programs pursue students to be physically active and move towards offering fitness and individual lifetime sport activities (Case, 2008). Students learn about physical activities that offer participation and fitness possibilities for a lifetime. Triathlon is one of the vehicles to teach the importance of lifetime fitness and the selection of a healthy lifestyle.

The rationale for the creation and delivery of a Triathlon unit for students in schools is three-fold:

1. The need to increase adolescents' physical activity.

2. To ensure an outdoor activity entitlement for every child.

3. To get students involved in a new growing sport.

The need to increase adolescents' physical activity

There is international consensus on considering that childhood obesity one of the most serious public health problems of this century. It is calculated that approximately one-quarter of school-age children in the world are obese. There are over 250 million obese in the world, mostly in industrialized countries, and projections estimate that the number of obese people will double in European countries in less than 10 years (Sociedad Española para el Estudio de la Obesidad SEEDO, 2013).

Of particular concern is the problem of overweight and obesity in children; the children of today are the adults of tomorrow. The latest data in Spain ${ }^{1}$ (2011) in children aged

1 Study ALADINO conducted by AESAN- Spanish Nutrition Agency
6-9 years (2010-2011) indicates that the prevalence of overweight is $26.1 \%$ and the prevalence of obesity is $19.1 \%$. This means that almost $46 \%$ of children under 6-9 years old are overweight (White Paper of Nutrition in Spain, Spanish Nutrition Foundation, 2013). In Spain, 27.6\% of children have a higher weight than the recommended one and the number is increasing (SEEDO, 2013).

Physical Education seeks physical activity participation and promotion among students and provides the necessary knowledge and understanding to keep their practise up in the future becoming active younghters. Physical activity is the objective:

"Physical education should facilitate pupils' participation in exercising and not to be worried about the levels of physical fitness they might achieve. Physical fitness should be understood as a consequence of regular exercising, the most important thing from a health point of view, as literature keeps highlighting in the last decade".

(Devís Devís, 2009, p. 76)

Studies (Telama, Yang, Hirvensalo y Raitakari, 2006) clearly show the importance of developing healthy habits and, particularly, during adolescence. According to Malina (2009): "Youth sports have been more recently invoked as a potentially important means to combat the worldwide epidemic of childhood overweight and obesity through the provision of regular physical activity".

The physical exercise of young people is a growing concern because of the problems of modern society. According to WHO (2003), Obesity is considered an epidemic of the XXI century due to lifestyle during childhood and / or adulthood. For this reason, one of the objectives of contemporary society is to immerse children in sport (Seifert, 2008). Each sport and technical managers have a responsibility to promote their sport, fostering an active lifestyle in young people and transmitting the values of sport.

"The sport of triathlon is a lifestyle and lifetime activity that has tremendous potential for physical education programs. Research has shown that triathletes generally start participating in triathlons after they leave high school or college. They select triathlons as a lifestyle choice because they prefer to stay active, healthy and fit. Triathlons provide various levels of competition while individuals participate in running, cycling and swimming events".

(Case, 2001, 2004)

In this way, triathlon federations and other sport governing bodies have an important role to play coordinating and promoting this sport in schools given the positive benefits it induces. 
To ensure an outdoor activity entitlement for every child

Tierra Orta (1996) defines outdoor education as a set of interdisciplinary activities that are developed in touch with nature from an educational, recreational and sport point of view, and with a certain degree of uncertainty in the environment. Triathlon is an activity that takes place in contact with the natural environment and is defined as the combination of swimming, cycling and running in which the swimming takes place in natural environment of open water (lakes, swamps, beaches, rivers ...). Triathlon is a physical activity performed outdoors which has demonstrated in the last years a growing trend to look at natural environment courses (Cross Triathlon European Tour “TNATURA “circuit” Xterra “, etc.).

According to Godbey (2009) being outside in natural surroundings may improve health and outdoor physical activities benefit participants. What is more, research has confirmed a link between physical activity that takes place outdoors and positive health outcomes and also an association between an indoor, sedentary lifestyle and negative health consequences (Godbey, 2009). This triathlon unit offers outdoor learning opportunities.

To get students involved in a new growing sport

Nowadays there are more than a million of triathlon practitioners in the five Continents. According to the International Triathlon Union (http://www.triathlon.org/, 2013) over the past decade the number of practitioners has grown at rates exceeding 20\% annually. At the current rate, by 2020 there will be over a hundred million citizens of the world who practice triathlon; no other sport has experienced such an increase in popularity. In the Sydney Olympics 2000, 19 countries broadcasted live Triathlon moving to 130 who did so in the 2012 London Olympics.

In the recent years, triathlon also has become a very popular sport in Spain experiencing a noticeable increase in participation and practice. The Spanish Institute of Sport (Consejo Superior de Deportes-CSD) in collaboration with the National Spanish Triathlon Federation (Federación Española de Triatlón, FETRI), the Autonomous Communities territorial federations and sport councils are promoting its practice changing the rules and distances to adapt the sport at all levels. School physical education classes now offer a diversified approach to developing human movement skills (Pangrazi, 2007). Traditional team sport skills are still part of the physical education program offerings but they are being offered along with a number of lifestyle sport and adventure activities (Case, 2008).

Triathlon is one of the sports included in the School Sport Program organized by the Spanish Institute of Sport (CSD) and the Sport Institutes' in the different Autonomous Com- munities. The spanish school sport program provides, fosters and develops sporting programs within Autonomous Communities schools. This is achieved through the co-ordination of regional programs across the school sport regions which provides the necessary network to cover the Autonomous Communities. School Sport's objective is to provide an opportunity for school students aged 6 years to 18 years to excel in their chosen sport through organised council district, Regional, Autonomous Community and National championships. Thus, there are competitions at youth level where students can participate aimed at increasing their practice in sport. Added to this is the inclusion in the National Program for the Promotion and Aid of School Sports (Programa Nacional de Promoción y Ayuda al Deporte Escolar-PROADES) also developed by the Spanish Institute of Sport, the National Spanish Triathlon Federation (FETRI) and territorial federations. The distances are shorter smaller categories and respectful child development and regulatory assistance for school age categories with recommended options. In addition, a campaign named "SERTRI" (Cadena Ser and FETRI) is promoting the practice of triathlon and its initiation at an early age. Competitions under this campaign have been held across Spain with the incorporation of triathlon "flash" and other possible combinations and distances.

\section{Unit of work "Lets get started with triathlon"}

\section{Description and implementation (delivery)}

Introduction

This learning unit is designed based on the characteristics of the socio-environment of a particular school and the profile of the physical education teacher, expert and practitioner of this sport. The Secondary School named "Antonio Hellin Costa" is located on the southeast coast of Spain, in Puerto de Mazarrón, Murcia. Mazarrón is a coastal area with a microclimate; it is surrounded by mountains which prevents strong winds from the north to enter the area and its situation, in the Gulf of Mazarrón between Cabo de Palos and Cape Gata, allows cold drafts entering the Atlantic through the Strait of Gibraltar to pass without affecting water temperature, remaining 5 degrees above the rest of the Mediterranean. Conditions of the environment and the ideal climate make this area the perfect place to practise triathlon in order to create healthy lifestyles. However, the uniqueness of each school allows adjustments required when organizing and developing a triathlon unit. If a school does not have access to a swimming pool or beach, then a duathlon can be conducted where the running and cycling components of the event are offered and the swimming segment deleted. 
The unit is designed under the framework of the School's educational project and it is included in the Physical Education syllabus for students in year 8 ( $3^{\circ}$ ESO) and year 9 ( $\left.4^{\circ} E S O\right)$ of Secondary Complusory Education. The unit was buit up of 12 lessons, 50 minutes each which were developed on a theoretical and practical basis following the scheme of an introduction-warming up, the development of the main contents of the session and a review-reflection about the work done and an introduction to the next session. The unit was conducted with a total of 98 (57 boys; 41 girls) 14-15 yearold students at a Secondary School (5) during the $3^{\text {rd }}$. school term (2013) taking advantage of the good weather. Two complementary outdoor activities were carried out in their own environment: an acuathlon on the beach and a bike ride around their natural environment. Moreover, the unit is enriched by the participation of students in duathlon, aquathlon and triathlon competitions held in the School Sports Programme organized by the Autonomous Community of the Region of Murcia and the Spanish Institute of Sport. Students also have the opportunity to participate in the regional competitions held by the Triathlon Federation of Murcia (FTRM). Therefore, lesson units were specifically developed to teach and emphasize the skills needed for a triathlon, duathlon, acuathlon event. For example, bicycle safety and riding techniques were taught in a cycling unit. The students worked on the technique and tactic of each of the three disciplines (swimming, cycling and running) and the different transitions. The unit also included contents of water and road safety, how to train different modalities and distances and how to deal with competitions. To sum it up, the students took part in an inter-school aquathlon competition held by the local council. The event was organized as a team event with the race segments provided in order to accommodate all the participants. Regarding the facilites and equipment, most of the lessons took place in the school's physical education sports facilities (classrooms, sports court and pavilion) adapting these. In the same way, the students and the teacher contributed to the unit with their own bikes in order to teach cycling and transitions with the celebration of a local ride with the support of the local police officers. Other equipment needed was provided by the school.

Contributions to key competencies

Key competencies refer to those that are considered essential to gain by students in their fulfillment, active citizenship, incorporation satisfactory to adulthood and the development of lifelong learning throughout life (Royal Decree 1631/2006):

- Language skills

- Mathematic skills

- Knowledge of the environment and interacting with the world
- Dealing with information skills

- Technology skills

- Social skills

- Cultural and artistic skills

- Learning to learn skills (metacogniton), autonomous skills and personal initiatives skills

Each of the different areas in compulsory education should contribute to the development of these skills. This unit contributes to the acquisition of the following skills:

- Knowledge and interaction with the world: connecting to the world. The proposed activities in nature are a mean of consolidating habits and attitudes of interaction with the environment, provide knowledge and skills on certain habits that are intended to accompany the students beyond their compulsory years of education and require the participation and active involvement of the person.

- Technology skills (digital competence): students learn to handle information in different media about the triathlon.

- Social and civic competence: The outcomes of outdoor physical activities are an effective mean to facilitate socialization and common coexistence, integration and respect, while contributing to the development of cooperation and solidarity. In addition, it contributes to respect the rules and regulations.

- Learning how to learn: the proposed activities promote autonomy and independence and allow the students to regulate their own learning and practice of physical activity in their free time, in an organized and structured way and provide longlife learning and activities.

- Autonomy and personal initiative: Outdoor activities present conflict, survival and overcoming risk situations that involve a self-assertion, self-control and selfmanagement (Ascaso et al, 1996). In the unit students are given prominence to the situations confronting them and making them manifest self-improvement, perseverance, responsibility and a positive attitude. It reinforces awareness of their own potential and limitations valuing individual differences due to the characteristics of the sport of triathlon which requires effort and improvement. This unit contributes to foster independent learners.

\section{Objectives}

Under the framework of the Key Competencies, the unit addresses the National Curriculum according to the curriculum policy at the first level: 
- Royal Decrees: Federal Goverment: RD 1631/2006 Compulsory Secondary Education

"To adquire knowledge and acceptance of ones body and others, respect differences, assure health habits and incorporate Physical Education and sports practice to enable personal and social development"

- Autonomous Communities Decrees: Decree 291/2007 Compulsory Secondary Education

"To adquire knowledge on how the human body works, respect differences, as well as, understand and value the effects of physical activity on health and a balanced diet incorporating the practice of sport to enable personal and social development".

Under the Curriculum Framework and the curriculum policy at a third level, the unit aims to the following goals:

- To understand and value the effects of engaging in daily physical activity to improve health status and quality of life.

- To know and experience the practical possibilities of Triathlon and its modalities practising physical activity in the natural environment and preserving it.

- To take part in Triathlon sport outside school through community links or sports clubs.

- To participate and collaborate in a triathlon, duathlon and / or aquathlon regardless of the skill level achieved.

- To improve cycling skills, respect the traffic regulations and promote the use of bicycles as a non-polluting commuting possibility.

- To positively value triathlon practice as a means recreational, leisure time and development and maintenance of health.

\section{Contents}

The unit is related to sports and activities in the natural environment under the curriculum guidelines (Decree No. 291/2007). From this first approach, we define the following specific contents:

Knowledge and understandings

- History and rules of triathlon.

- The segments and triathlon transitions.

- Bike safety in triathlon and bike commuting.

Skills for Physical Activity

- Warm up in triatlon and its modalities (duathlon, aquathlon......)
- Technique of the different segments: swimming, cycling and running.

- Technique of triathlon transitions and races.

- Management, use and basic maintenance of the bike.

Life, self-management and Interpersonal Skills

- Positive attitude towards the practice of triathlon as a recreational, leisure time and development and maintenance of health point of view.

- Internalization of the importance of the natural environment as a means of enjoyment and entertainment. Respect for the environment and care of it.

- Respect safety standards and road traffic and value the use of the bicycle as a healthy and environmentally friendly transport.

- Active participation in the sport of triathlon, regardless of skill level achieved knowing the limitations of each.

Learning activities

\section{Session 1- TRIATHLON}

- Objectives: To present the unit and awake the interest of students in learning and experiencing the sport of triathlon and its modalities.

- Activity 1: with some notes prepared for the unit and through a power-point exposure, explanations are made about the history, features, modes, transitions, regulation and triathlete's equipment.

- Activity 2: Triathlon website: Internet browsing projecting the most interesting pages related to triathlon (www. triatlon.org, www.trimurcia.org, www.triathlon.org...).

Session 2- WARMING UP IN TRIATHLON AND SWIMMING SEGMENT

- Objectives: To learn and experience the warming up in triathlon, to work on the swim in triathlon: front crawl swimming and open water swimming and water safety rules and regulations (in the unit it is not intended to teach students how to swim).

- Activity 1: Watch an underwater video of the swim in the triathlon that is held at the students locality (Puerto de Mazarrón) which involves local, national and international triathletes (Triatlón Fuenteálamo); analysis of front crawl and comments on open water swimming, safety rules and regulations regarding this segment in triathlon and aquathlon.

- Activity 2: Warm up in triathlon: students in groups decide on how the warm up should be in a triathlon and its modalities. 


\section{Session 4 - THE BIKE}

- Objectives: To know the safety rules riding a bike, basic maintenance and bicycle use for commuting and environmentally healthy and friendly way of transport.

- Activity 1: Interactive activity by projecting the contents of a CD released by the MAFRE Foundation and the Institute of Road Safety "The bicycle, your passion, your safety" regarding traffic rules and road safety. Explain the rules regarding the bike segment in triathlon and duathlon.

- Activity 2: Look at the basic aspects of bike maintenance (handlebar and saddle height, punctures, repair, etc..).

- Activity 3: Demonstration of how to repair a puncture and change a tube. Practice puncture repair in groups.

\section{Session 5 - CYCLING SEGMENT}

- Objectives: Cycling in triathlon: basic techniques.

- Activity 1: Conduct a specific warm up.

- Activity 2: Understanding and testing of basic skills on the bike: up, down, stop, turn, shift gears..

- Activity 2: In groups and taking turns, performe a skill circuit with the bike.

- Activity 3: Relay: the same groups doing the same circuit bike skill in the school's courtyard with a transition area. The team that finishes first wins.

\section{Session 6 - RUNNING SEGMENT}

- Objectives: Running in triathlon: basic techniques.

- Activity 1: Games that involve running

- Activity 2: Running technique exercises (skipping knees up, heels back, stride), progressive runs and changes of pace.

- Activity 3: In groups, a group goal of running a certain number of laps around the school's courtyard. The team that carries it out in the shortest time wins. They agree on how many laps each of them do. Everyone in the team must participate.

\section{Session 6 - TRANSITIONS}

- Objectives: Transitions in triathlon: basic techniques.

- Activity 1: Discussion of the transitions by referring to relevant aspects of the rules.

- Activity 2: Practice of duathlon transitions circuit.

- Activity 3: Relay in groups: duathlon circuit with transition area and exchanging a number. The team that finishes first wins.
Session 7 - TRANSITIONS

- Objectives: Transitions in triathlon: basic techniques and practical test.

- Activity 1: Explanation of the practical test to be performed: start and complete 10 strokes on a fit-ball, entrance to the transition area (T1), exit and two lap bike ride, correct entrance to the transition area (T2), 1 lap run to the finish line.

- Activity 2: Practice transitions circuit in groups.

- Activity 3: Individual procedure test.

Session 8 - TRIATHLON: KNOWLEDGE AND UNDERSTANDING

- Objectives: To sit an exam and assess knowledge and understandings.

- Activity 1: Knowledge and understanding test.

- Activity 2: Assess on the unit: feedback on the implementation

- Activity 3: Sharing comments on the unit.

\section{Comments:}

- Competition on the beach: aquathlon. This is a school competition event which involves swimming and running. The goal is to finish the unit with an event that encourages students to put their knowledge and understanding into practise, involve them in the organization and contribute to their confidence so that they participate in the sport outside the school setting.

- The cycling route is held in the nearby natural environment. This cycling route and bicycle-related sessions are conducted as part of the unit or as a separate one. Students have watched videos and performed tasks related to safety cycling reminding them to use their helmet and respect the traffic rules, etc. The local police guide the students throughout the cycling route in the nearby natural environment.

- Interdisciplinary contents are part of this unit: environmental education, health education....

- This unit represents the development of proposals of activities for a particular school. Each school and each teacher can adapt to changing circumstances, suppressing activities and / or adding new ones. In this way you can reduce or increase the number of sessions. The aim is to bring triathlon to the school setting presenting it as a healthy activity to develop in their free time in the natural environment. 


\section{Methodology}

Underpinned by a constructive learning framework, the delivery of this unit leads to the acquisition of significant and useful learning with an active and participatory methodology. It is about creating a motivating environment that sparks the desire to practice this sport. Efforts will be made nondirective pedagogy situations posing for exploration of different practices especially in the sessions on transitions and bicycle, learning by discovery or basic indications for open search. Students work in pairs and groups in order to achieve common goals. For the competition to be held on the beach, students compete as a team fitting in two different possibilities: all team members perform all segments or each segment is performed by a single team member.

\section{Resources and materials}

Environmental Resources

The outdoor activities of the unit are developed in the natural environment near the school. We have chosen the closest beach to school which offers great security and less risk (" $B a$ hia Beach"). The students walked to this beach (2 km). The bike ride was celebrated on the tracks in area near the school and in collaboration with local council police.

\section{Material Resources: equipment}

Triathlon is a sport that requires different material which is minimized in the unit. For the first two theoretical sessions have used new technologies with performances in "powerpoint", the use of different web pages (www.trimurcia.org, www.triatlon.org, etc..), video tutorials, competitions and the program "Guide "offered by the Spanish Triathlon Federation. (http://tecnificacion.triatlon.org/programa- guide). For the practical sessions students rode their bikes to school each day. Not every student had a bike so we used all of them in the different groups organizing students into smaller groups for practices. The material for the bike puncture repair lessons (tubes, patches, tools, etc..) was provided by the school as well as other necessary equipment for the competition (rubber bands, swim caps, cones, etc.). The practical sessions of cycling, running and transitions have been developed in the school's sports courtyard.

\section{Learning outcomes}

\section{$\underline{\text { Knowledge and understanding }}$}

- Identifies the origins, triathlon distances, modalities and basic rules and regulations.
- Identifies the traffic regulations on the use of the bicycle and safety standards in the natural environment.

- Lists the equipment necessary to practice triathlon.

\section{$\underline{\text { Skills for Physical Activity }}$}

- Performs warm-up for triathlon/duathlon and /or aquathlon.

- Performs basic actions bike handling and transitions.

- Performs a triathlon/acuathlon/duathlon.

- Participates actively in the practical sessions regardless of skill level ever achieved knowing the limitations of each.

\section{$\underline{\text { Life, self-management and Interpersonal Skills }}$}

- Values positively triathlon/acuathlon/duathlon as a recreational and leisure time sport which contributes to develop and maintain health.

\section{Research: focus group}

\section{Focus group}

Focus groups are distinctly useful as a research technique that permits in-depth examination of complex issues. We used this tool to explore in detail students' awareness, behaviours, concerns, beliefs, experiences, motivations, and intentions related to Triathlon. We look at students' perceptions, knowledge, and experiences related to the triathlon unit in order to understand these at a deeper level. In this sense, focus group research-a qualitative research method that uses guided group discussion-was chosen as the best method for examining the impact of this triathlon sport unit on students. This interview format suited the research for the purpose of elaborating students' perspectives on Triathlon: "Participants are selected to represent common perspectives or a range of different philosofies or viewpoints associated with the research questions" (Enis \& Chen in Armour \& MacDonald, 2012, pp .220).

\section{Background and purpose of study}

The interest was addressing issues such as what did the unit of triathlon mean to the students and did it have any effect on the students' physical activity behaviours. The results of this set of focus groups will inform the design of the future units of Triathlon within school-based Physical Education. Therfore, the goal of this second phase of the formative research was to:

- Explore students' perceptions of triathlon

- Assess students' knowledge of triathlon 
- Explore students' knowledge related to triathlon

- Investigate students' perceptions of triathlon

Profile of Participant Population

One key to conducting productive focus group research is maintaining individual group homogeneity as much as possible in an effort to help participants feel comfortable expressing their thoughts. In total, 16 students participated in the focus groups conducted during May and June 2013:

- Discussion groups: 2 homogenous groups: Participant inclusion criteria: nomination; the teacher nominated the students which would make good participants (familiar with the topic, known for their ability to respectfully share their opinions, and willing to volunteer) out of 98 students Year 10 (15/16 years old).

- 1 discussion group "A" of 8 students: Year 10 (15/16 years old)

- 1 discussion group of "B" of 8 students: Year 10- (15/16 years old)

- Time: 55 minutes (a lesson)

- All participants completed a consent form

- Transcription of all focus group tapes (with notes).

- The students-participants completed a short demographic questionnaire: age, gender and attributes important for correlation with focus group findings.

- The teacher-moderator: script to welcome participants, remind them of the purpose of the group and also sets ground rules (you do the talking, no right or wrong answers, what is said will be recorded but will not identify anyone and will stay among us).

- 8 pre-determined questions:

1. What did you know about triathlon before the unit?

2. With the information you have now, would you like to take part in a triathlon?

3. After receiving the lessons on triathlon, would you like to continue with triathlon and practice it?

4. What do you think about the knowledge and understanding you have now on triathlon? Has it improved?

5. What do you think about the lessons?

6. Do you think theory and practice were related? Enough equipment? Clear delivery?

7. What do you think about the assessment?

8. Which of the activities did you find the most difficult?

9. Add any suggestions you consider.

\section{Some answers.......}

1. What did you know about triathlon before the unit? Almost nothing, a little, nothing.......
2. With the information you have now, would you like to take part in a triathlon? Yes......No.....

3. After receiving the lessons on triathlon, would you like to continue with triathlon and practise it? Yes but.....

4. What do you think about the knowledge and understanding you have now on triathlon? ¿Has it improved? A little, quiet a bit....

5. What do you think about the lessons? Interesting, very interesting, slightly interesting....

6. Do you think theory and practise were related? Enough equipment? Clear delivery? Highly related theory to practice, almost always enough equipment, very well delivered.....

7. What do you think about the assessment? Suitable and very suitable....

8. Which of the activities did you find the most difficult? "None of them, they were all very easy", "Endurance tasks...", "Everything!", "The duathlon circuit we did in the sports pavillion", "The acuathlon at the beach"

9. Add any suggestions and or/opinions you consider: "Triathlon is really cool because you get fit and gain endurance", "I have really enjoyed this unit because you have to have a lot of endurance", "Triathlon is a very interesting activity and you need to be fit", "Triathlon is a fun activity", "It's great because you get in good shape and fit", "I have enjoyed the unit because I have learnt new things", "Fun" "Great to learn", "I would like to be a professional triathlete"....

Suggestions: "Practise the swimming more", "Practise the practical exam more...more training the acuathlon", "We should have a swimming-pool inlat the school", "More leaving the school and going out to do activities on triathlon", "Excursions" "More outdoor activities" "More mountain bikes route", "Have bicycles at the school to use", "More practical lessons", "Nothing, it all seems fine to me.....well maybe do more activities at the swimming-pool and beach....more outdoor activities".

The process used to analyze this set of focus groups is based on that recommended by Krueger (1988), systematic and verifiable. We used an excel database, a spreadsheet for each group and one sheet per question, and processed each group briefly at its conclusion, then developed a total picture of the two groups, and finally considered each group and responses to the specific question: common themes, points of interest, and tendencies among participants' comments. The final task was to examine the conclusions drawn from the data in terms of implications for the design of the future implementation of Triathlon within school-based Physical Education. 


\section{Findings and conclusions}

The following common themes were found: Triathlon as an interesting activity, a hard endurance and healthy sport. Overarching themes indicated students had little knowledge on triathlon before the unit which increased significantly after its implementation; students think they are capable of taking part in a triathlon after the unit and would like to continue with triathlon; the unit well related theory and practice with suitable equipment, very suitable delivery and very suitable assessment and marking.

The development of this unit has achieved greater active participation in physical exercise in the natural environment. Triathlon is an activity that enables the creation of healthy habits and proper use of leisure time. Students seem to have become aware of the sport of Triathlon and demonstrate outcomes on knowledge, understanding and basic skills related to Triathlon. This unit has provided adolescents the oppor- tunities to learn these skills and practise this sport beyond school based Physical Education (triathlons as a lifestyle choice) and increase their levels of physical activity. It offers to learn about physical activities that promote participation and fitness possibilities for a lifetime. Its initial development may seem conditioned upon location and characteristics of very specific material, but with appropriate modifications it can be adapted perfectly and included in the school-based Physical Education syllabus.

\section{Future considerations}

The sport of triathlon has a tremendous potential for physical education programs. Students can learn about physical activities that offer participation and fitness possibilities for a lifetime. However, further research is needed in order to study the impact of Triathlon in school-based physical education.

\section{Refrences}

1. Armour, K. \& Macdonald, D. (2012). Research methods in Physical Education and Youth Sport. USA: Routledge.

2. Anton, P. \& Sainz, M. (1989). What can I do in my class with the bike? Specific skill games. Journal of Physical Education. Renewal of theory and practice, 25, 25-32.

3. Ascaso Martorell, J. Casterad Seral, J. Generelo Lanaspa, E. Guillen Belts, R. Lapetra Costa, S. \& Tierz Garcia, M. P. (1996). The extracurricular sport and physical activity in schools. Outdoor activities (activities in nature). Madrid: MEC.

4. Ballesteros, J. (1987). El libro del triatlón. Madrid: Arthax S.L.

5. Case, R. \& Branch, D. (2001). Event marketing: An examination of selected demographic and psychographic data of participants competing in the world's foremost triathlon event. International Sports Journal, 5(1), 118-127.

6. Case, R. (2001). An Examination of the Economic Impact of the 2000 Xterra World Championship Triathlon. Paper presentation at the Florida State University Sport Management Conference, November 1-3.

7. Case, R. (2004). An Examination of the Demographic and Direct Spending Data Associated with the 2004 Nissan Xterra World Championship. Poster presentation at Research Day, Old Dominion University.

8. Case, R. (2008). Triathlon events as possible activities for your physical education program. VAHPERD Journal: Virginia Association for Health, Physical Education and Dance. Education, 4, 29.

9. Darst, P.W. \& PangrazI, R. P. (2006). Dynamic Physical Education for Secondary School Students. Boston: Benjamin Cummings.

10. Decree No291/2007, of September 14, which establishes the curriculum of Secondary Education in the Autonomous Community of the Region of Murcia. BORM no. 221, 27179-27303.

11. Dejager, D. (2006). Adventure racing CORE: A non-traditional approach to the physical education lesson. Journal of Physical Education, Recreation and Dance, 6, 25-33.

12. Devis Devis, J. (2009). Health paradigm in Physical Education. Paper in Physical Activity and Health Education in European Schools. Edited by González-Gross, et al. Madrid: Polythecnic of Madrid. 74-79.

13. Didier L. \& Didier, B. (2001). El Triatlón. Barcelona, INDE

14. Educational project secondary school "Antonio Hellin Costa" in IES

annual general programming Hellin Antonio Costa (2012/2013). Not edited.

15. Edwards, S. (2002). Triathlons for women. Training plans, equipment, nutrition. USA: Velo press. $3^{\text {rd }}$. Edition.

16. Ehrler, W. (1994). Triatlón: técnica, táctica y entrenamiento. Barcelona: Paidotribo.

17. Gil Fraguas, L. Gutierrez, J. \& Sánchez, F. (2000). Manual Técnico de triatlón. Madrid: Gymnos.

18. Godbey, G. (2009). Outdoor Recreation, Health and Wellness: Understanding and Enhancing the Relationship. http://www.rff.org/documents/RFF-DP-09-21.pdf

19. Granero Gallegos. A. (2007). A taxonomic conceptual approach and physical activities in the natural environment. Lecturas, Educación Física y Deportes, Revista Digital, 107, 1.

20. Hawman, C. (2012). OAA Matters. Physical Education Matters. Official Journal of the Association for Physical Education, 2 (7), 9-10.

21. Krueger, R.A. (1988). Focus groups: A practical guide for applied research. Beverly Hills, CA: Sage.

22. Lago Hidalgo, J. (2002). The triathlete's training model XXI century. Lecturas, Educación Física y Deportes, Revista Digital, 89, 1.

23. Organic Law 2/2006, of 3 May, on Education. BOE. 106, 17158 -17207.

24. Machota Blas, V. E. (2012). A unit proposal of triatlon within the School. EmásF, Digital Magazine of Physical Education, 19, 115-129.

25. Machota Blas, V. E \& Nimes Perez, T. (2008). Fun triathlon. Paper presented at the 5th National Congress and 3rd International Iberoamerican School Sports, Dos Hermanas Seville, Spain. Dos Hermanas (Seville-Spain), 485-516.

26. Mafre Foundation (2002). The bicycle, your passion, your safety. CD released by the Institute of Traffic and Road Safety. Valencia: University of Valencia.

27. Moorman, M. Schlatter, B. \& Hurd, A. (2007). Adventure Recreation: Coming Soon to Your Community. Journal of Physical Education, Recreation and Dance, 9, 22-26.

28. Morgan, D.L. (1988). Focus Groups as Qualitative Research. Thousand Oaks, CA: Sage

29. Morgan, D.L. (1992). Designing focus group research. In Tools for Primary Care Research, ed. M Stewart, et al, pp. 177-93. Thousand Oaks, 
CA: Sage.

30. Morgan, D.L. (1993). Successful Focus Groups: Advancing the State of the Art. Thousand Oaks, C.A: Sage.

31. Muńoz Diaz, J. C. (2010). The core competencies. Development through a physical education teaching unit. EmásF, Digital Journal of Physical Education, 1, 3, 19-39.

32. Painter, C. (2005). Up to the challenge: XTERRA opens new horizons for inter-city kids. Triathlete Magazine, 134.

33. Pangrazi, R.P. (2007). Dynamic Education for Elementary School Children. Boston: Benjamin Cummings. Gale Copyright: Copyright 2008 Gale, Cengage Learning.

34. Royal Decree No1631/2006, of 29 December, which establishes the core curriculum for the Compulsory Secondary Education in Spain. BOE. 106, 677-773.

35. Sociedad Española para el Estudio de la Obesidad SEEDO (2013). Newsletter No 3 April 2013 www.seedo.es
36. Spanish Federation of Triathlon (2007). Triathlon for fun. A teaching unit for Physical Education. Madrid: FETRI.

37. Tierra Orta, J. (1996). Recreational activities in nature. In A. Rosales Soto, (Ed.), Primary Education: nature activities. Huelva: Huelva University

38. Torres, B. \& Portoles, E (2007). Young triathletes. Introduction to Triathlon. Madrid: Spanish Triathlon Federation and Ministry of Sports Community of Madrid.

39. Vílchez Conesa, P. \& Nimes, T. (2011). Efficiency of Resources on triathlon promotion according to previous triathletes experiences. Sportraining, Technical journal of competitive sport, 37.

40. Wainwright, N. \& Williams, A. (2012). Adventurous Activities and Physical Education in Wales, Physical Education Matters. Official Journal of the Association for Physical Education, 2, 7, 51-54. 